\title{
Design and Performance Analysis of a Triple Band Micro-Strip Patch Antenna with CPW-Fed
}

\author{
Rahul Tiwari ${ }^{\mathrm{a}}$, Laxman Yogi ${ }^{\mathrm{b}}$, Ashish Bagwari ${ }^{\mathrm{c}}$, Vivek Singh Kushwah ${ }^{\mathrm{d}}$ \\ ${ }^{a}$ Assistant Professor, Dept. of Electronics Engineering, Medi-Caps University, Indore, India \\ ${ }^{b}$ Research Scholar, Dept. of Electronics Engineering, Medi-Caps University, Indore, India \\ ${ }^{c}$ Assistant Professor, Dept. of Electronics \& Communication, WIT, UTU, Dehradun \\ ${ }^{d}$ Assistant Professor, Dept. of Electronics \& Communication, Amity University, Gwalior
}

Received: 03 July 2018; Accepted: 16 October 2018; Published: 08 January 2019

\begin{abstract}
A compact microstrip patch antenna (RMPA) using systematic coplanar waveguide (CPW-Fed) triple printed antenna has designed for WiMAX/WLAN applications in this paper. A prototype CPW-Fed antenna was fabricated with FR4 Substrate with the dielectric constant of 4.4 and thickness $\mathrm{h}=1.6 \mathrm{~mm}$. The antenna primarily consists of the symmetrical coplanar waveguide with rectangular slotted patch and excite by a $50 \Omega$ CPW feed line for impedance matching to generate wide triple operating bands. This antenna is suitable for the range from $2.39-2.75 \mathrm{GHz}, 3.4-3.7 \mathrm{GHz}$ and $4.6-6.9 \mathrm{GHz}$. It is designed miniaturized CPW-Fed microstrip patch antenna has a compact size $20 \mathrm{~mm} \times 35 \mathrm{~mm}$. In this paper researcher has focused on to improve the gain, impedance bandwidth and also have lower return losses, better impedance matching. The simulated results show that the proposed antenna has achieved wider bandwidth with satisfactory gain by introducing a stub with CPW-Fed in the assistant of a rectangular slot in the upper layer.
\end{abstract}

Index Terms: Triple band, CPW-Fed Microstrip antenna, FR-4 substrate, CST Software, VSWR, WiMAX, WLAN applications.

(C) 2019 Published by MECS Publisher. Selection and/or peer review under responsibility of the Research Association of Modern Education and Computer Science

\section{Introduction}

Microstrip patch antenna (MPA) technology came into existence in the 1970s [1]. The IEEE 802.16d technology is a wideband wireless data communications technology, provided that extraordinary speed data

* Corresponding author. Tel.:

E-mail address: rahulcktd@gmail.com 
over a wide-ranging area. It is a technology for point to multipoint, free space networking [2]. Recently, there is growing research activity on multi-frequency and wideband antennas for various wireless applications such as WLAN (Wireless Local Area Network) or WiMAX (Worldwide Interoperability for Microwave Access) $[3,4]$. Current wireless communication systems wideband and small shape patches are in great demand for both commercial and military applications [5]. In this techniques antenna designed for L-band applications using asymmetric CPW with an inverted L-shaped strip. It has gain $8 \mathrm{dBi}$ at $1.5 \mathrm{GHz}$ [6]. The researcher has designed a CPW-fed antenna for WLAN. It has achieved $400 \mathrm{MHz}$ bandwidth $(5.02 \mathrm{GHz}$ to $5.42 \mathrm{GHz})$ at $10 \mathrm{~dB}$ return loss. It is getting a peak gain of $8.5 \mathrm{dBi}$. It attains antenna size of $37 \mathrm{x} 37 \mathrm{x} 1.6 \mathrm{~mm}^{3}$ [7]. The authors have designed a slot antenna using CPW-fed. It is performed for miniaturization and circular polarization. It shows the bandwidth of $5.2 \%$ and peak gain is $1.8 \mathrm{dBi}$. Its antenna size is $60 \times 30 \times 1.6 \mathrm{~mm}^{3}$ [8]. The authors have designed an open slot antenna using CPW-fed for wireless communication. It has Bandwidth of $5.330 \mathrm{GHz}$ $(2.13-7.46 \mathrm{GHz})$ and covered $2-6 \mathrm{GHz}$ frequency range for WiMAX and getting peak gain of $5.3 \mathrm{dBi}$ and antenna dimensions are $50 \times 50 \mathrm{~mm}^{2}$ [9]. The researcher has designed octagonal slotted shaped using coplanar waveguide fed. The experimental results show impedance bandwidth is from $2.40 \mathrm{GHz}$ to $2.46 \mathrm{GHz}$ and 3.2 $\mathrm{GHz}$ to $6.2 \mathrm{GHz}$, which is covered with the WiMAX, WLAN applications. The dimensions of the antenna are 20 x $20 \mathrm{~mm}^{2}$ [10]. The researcher has designed a microstrip patch antenna with the defected substrate using CPWfed for $\mathrm{C}$ and $\mathrm{X}$ band applications. This covered frequency band from 4.5 to $13.5 \mathrm{GHz}(9.0 \mathrm{GHz})$ and overall size of the antenna is $36 \times 42 \times 1.6 \mathrm{~mm}^{3}$ [11]. In this paper discus about the defected substrate and its size $36 \mathrm{~mm} \times$ $42 \mathrm{~mm} \times 1.6 \mathrm{~mm}$. The antenna is designed for c-band and x-band [12]. In the paper researcher has designed a 20 $\mathrm{mm} \times 37 \mathrm{~mm} \times 1.56 \mathrm{~mm}$ dual band antenna form 2.62 to $2.73 \mathrm{GHz}(110 \mathrm{MHz})$ and from 3.02 to $7.30 \mathrm{GHz}(4.2$ $\mathrm{GHz}$ [13].

\section{Parametric Analysis and Simulation Results of a Symmetric Cpw-Fed Microstrip Patch Antenna}

The frequency range of operation $\left(f_{0}\right)$ is the selection of the resonant frequency of the antenna must be selected properly. The resonant frequency range selected for our design is $2 \mathrm{GHz}-8 \mathrm{GHz}$. The dielectric constant of the substrate of an antenna (cr) is the selection of dielectric material is very important because it does reduce the size of the antenna. It is essential that the antenna is not bulky. The overall size of the proposed antenna is $20 \mathrm{~mm}$ x $35 \mathrm{~mm}$. The optimized parameters of the proposed CPW-fed tilted symmetrical rectangular printed antenna after numerically studied on CST Microwave Studio are listed in Table 1.

Table 1 shows the parametric parameters values

\begin{tabular}{|c|c|c|c|c|}
\hline Parameters & Antenna1 (mm) & Antenna $2(\mathrm{~mm})$ & Antenna $3(\mathrm{~mm})$ & Proposed antenna $(\mathrm{mm})$ \\
\hline $\mathrm{W}$ & 20 & 20 & 20 & 20 \\
\hline L1 & 9 & 9 & 9 & 9 \\
\hline L3 & $\begin{array}{ll}------- \\
\end{array}$ & $\begin{array}{ll}------ \\
\end{array}$ & ------- & 4 \\
\hline W1 & 7.0225 & 7.225 & 7.225 & 7.225 \\
\hline $\mathrm{Lg}$ & 11.2 & 11.2 & 11.2 & 11.2 \\
\hline $\mathrm{d}$ & 2 & 2 & 2 & 2 \\
\hline $\mathrm{L}$ & 35 & 35 & 35 & 35 \\
\hline $\mathrm{L} 2$ & ------- & 10.5 & 10.5 & 10.5 \\
\hline L4 & 3.3 & 3.3 & 3.3 & 3.3 \\
\hline $\mathrm{Wg}$ & 8.79 & 8.79 & 8.79 & 8.79 \\
\hline Wf & 3.39 & 3.39 & 3.39 & 3.39 \\
\hline W2 & ---- & & 5.625 & 5.625 \\
\hline $\mathrm{g}$ & 0.4 & 0.4 & 0.4 & 0.4 \\
\hline P1 & 3 & 3 & 3 & 3 \\
\hline $\mathrm{S}$ & ------------- & ----------- & -------- & 1 \\
\hline $\mathrm{P} 2$ & 3 & 3 & 3 & 3 \\
\hline $\mathrm{h}$ & 1.6 & 1.6 & 1.6 & 1.6 \\
\hline
\end{tabular}




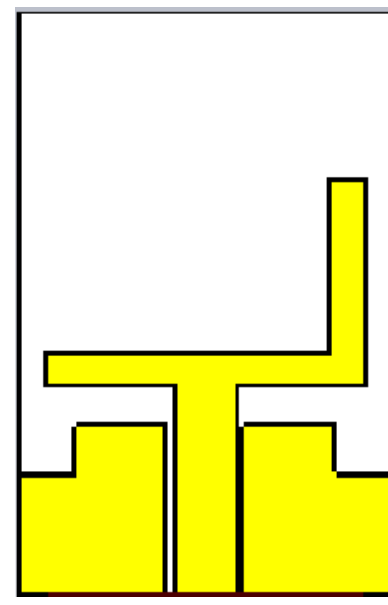

(a) Antenna1

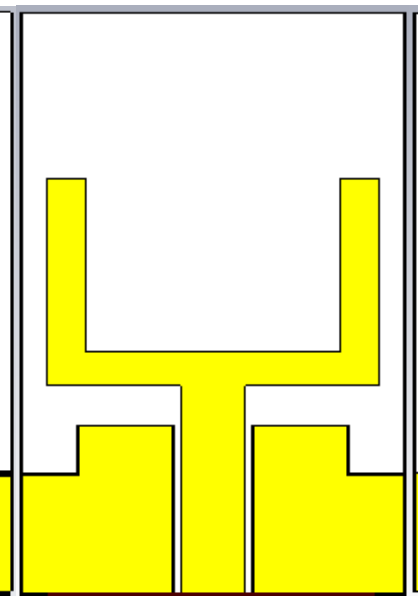

(b) A ntenna2

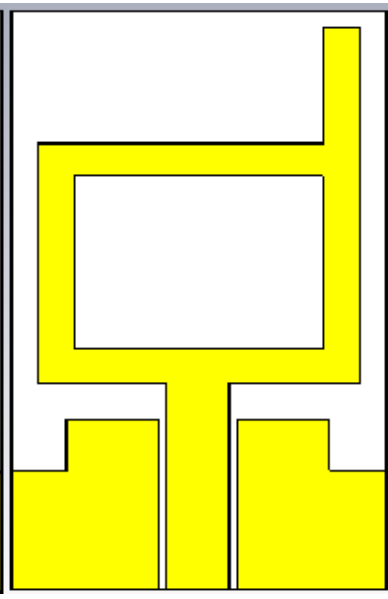

(c) Antenna3

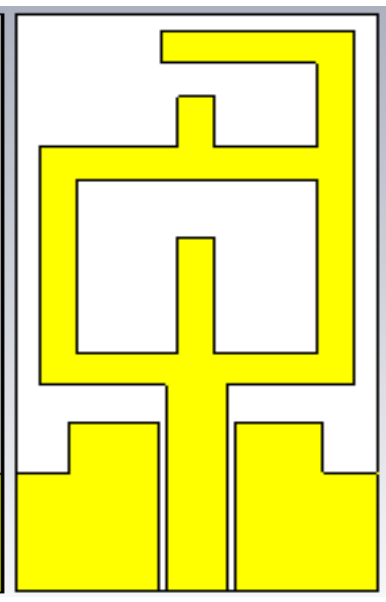

(d) Proposed antenna

Fig.1. Evolution of the proposed symmetrical rectangular-shaped antenna.

The proposed antenna is shown in Fig 2. The proposed antenna is designed using CST Microwave Studio simulation software and its physical dimensions are $\mathrm{W}=20 \mathrm{~mm}, \mathrm{~L}=35 \mathrm{~mm}$, Where $\mathrm{L} 2=10.5 \mathrm{~mm}, \mathrm{~L} 1=9 \mathrm{~mm}$, Width of the feed $=3.39 \mathrm{~mm}$ and $\mathrm{d}=2 \mathrm{~mm}$, Gap distance is $\mathrm{g}=.4$ and $\mathrm{Lg}=11.2 \mathrm{~mm}$. in the proposed antenna researcher used the FR-4 substrate with $\varepsilon_{\mathrm{r}}=4.3$ with height $1.6 \mathrm{~mm}$. The Proposed antenna has better impedance matching which corresponds to $50 \Omega$ characteristic impedance.

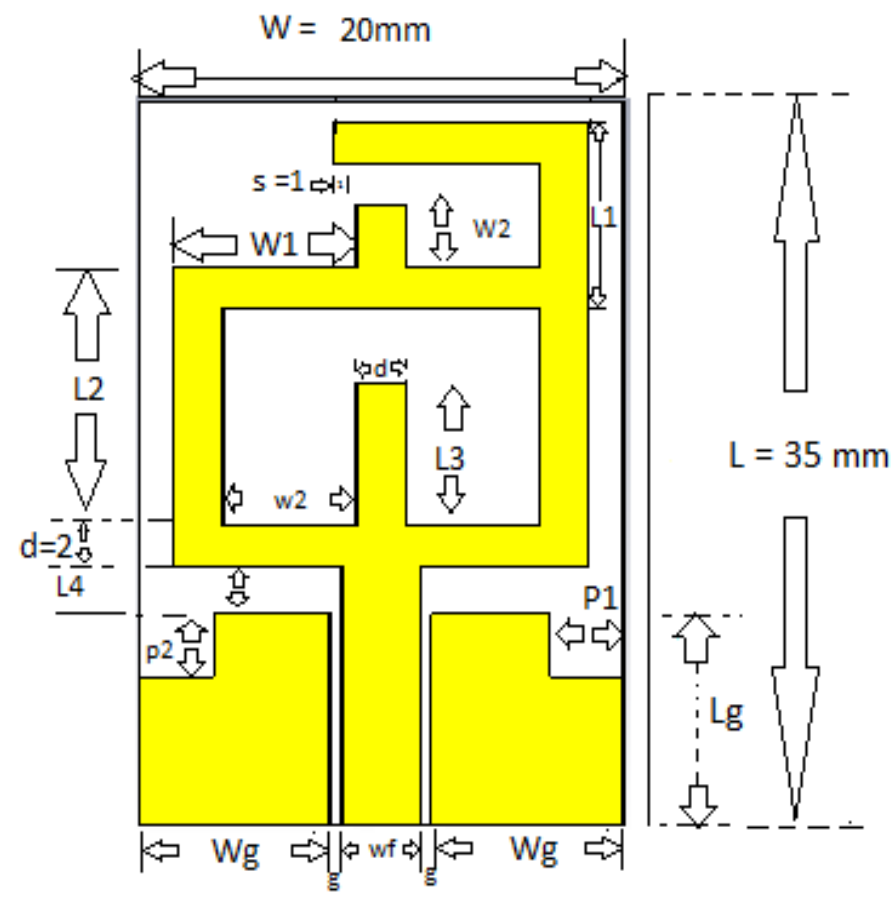

Fig.2. Schematic diagram of the proposed antenna structure 


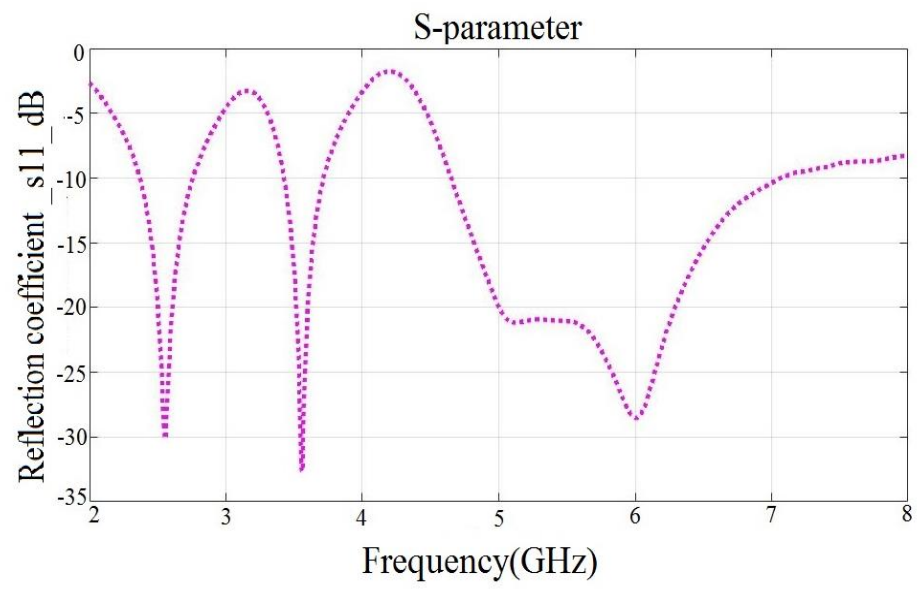

Fig.3. EM Simulation $|\mathrm{S} 11|$ of the proposed antenna

In Fig. 3 the Return loss of proposed antenna shown, the first frequency band from $2.37 \mathrm{GHz}$ to $2.75 \mathrm{GHz}$ has return loss is $-23.71 \mathrm{~dB}$ and in the second frequency band from $3.4 \mathrm{GHz}$ to $3.7 \mathrm{GHz}$ has return loss $-36.1 \mathrm{~dB}$ and in last frequency band from $4.6 \mathrm{GHz}$ to $7.0 \mathrm{GHz}$ has return loss $-36.1 \mathrm{~dB}$.

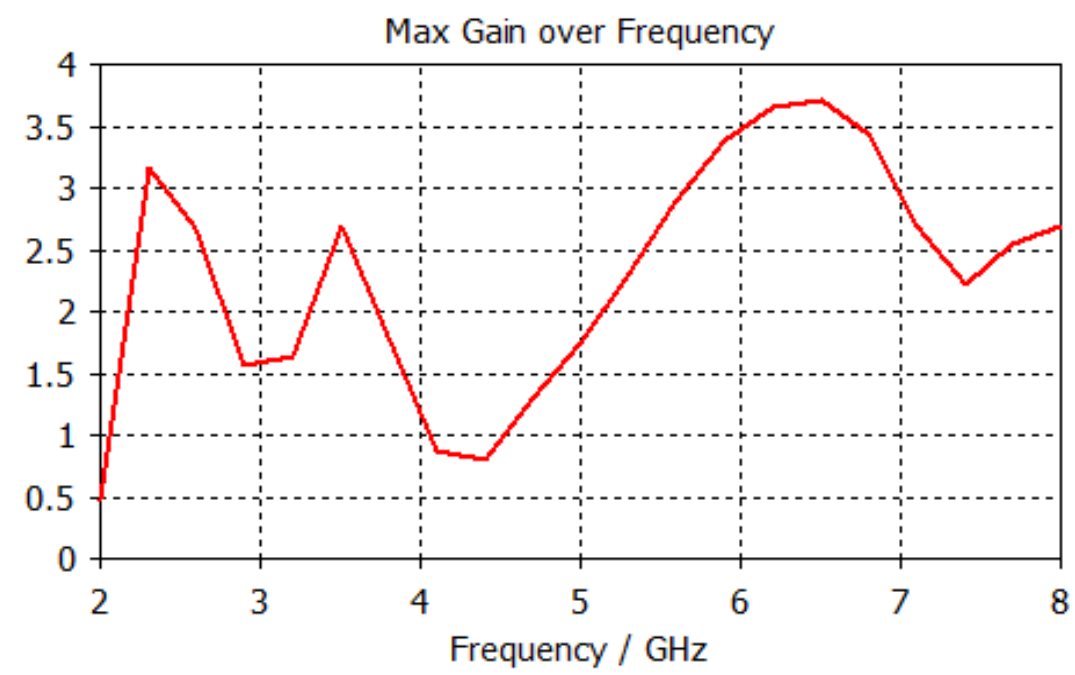

Fig.4. Gain of the proposed antenna

In Fig 4 shows the gain plot of the proposed antenna, the first frequency band from $2.37 \mathrm{GHz}$ to $2.75 \mathrm{GHz}$ has Gain is $3.16 \mathrm{dBi}$ (Max) and in the second frequency band from $3.4 \mathrm{GHz}$ to $3.7 \mathrm{GHz}$ has Gain is $2.70 \mathrm{dBi}$ (Max) and in last frequency band from $4.6 \mathrm{GHz}$ to $7.0 \mathrm{GHz}$ has Gain is $3.74 \mathrm{dBi}$ (Max). 

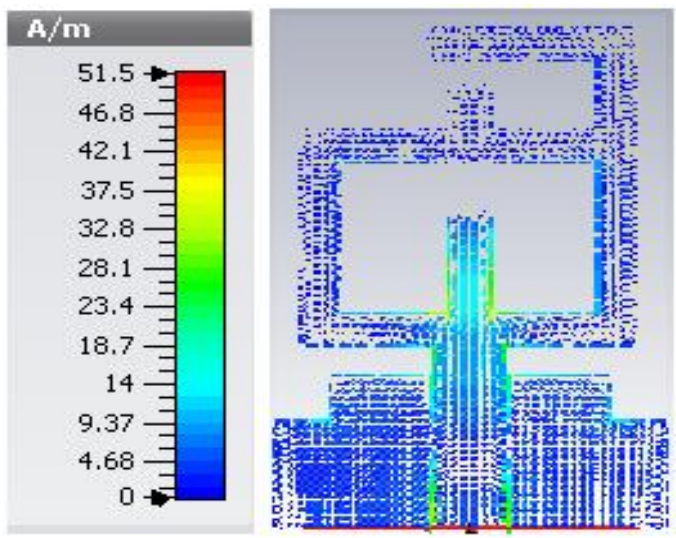

(a)
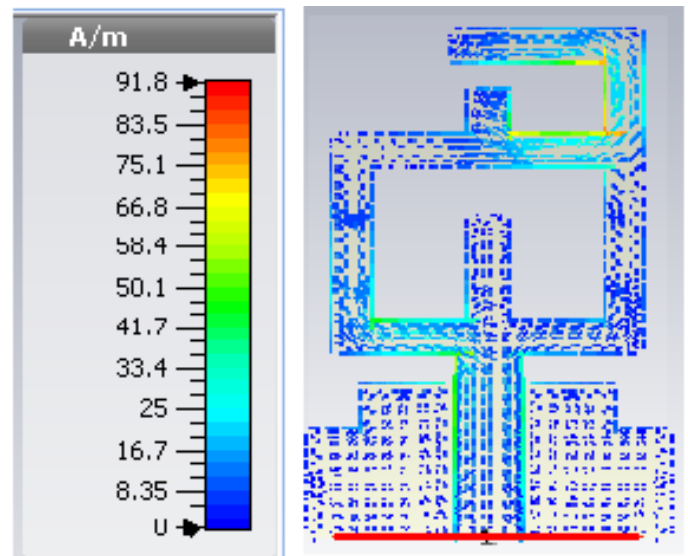

(c)
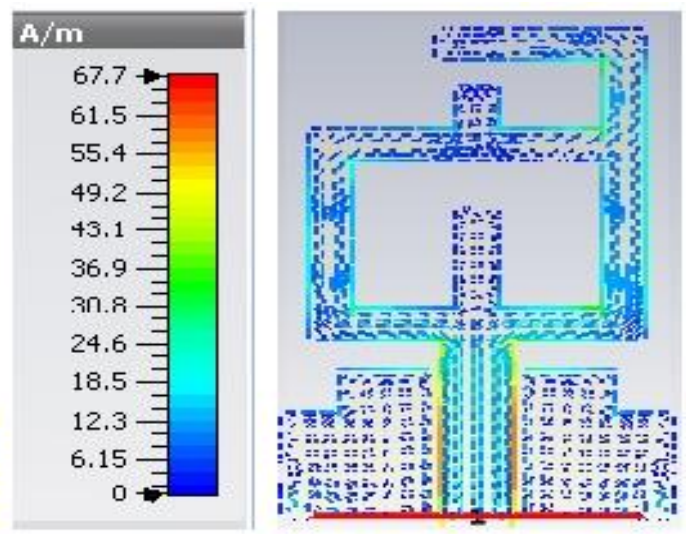

(b)
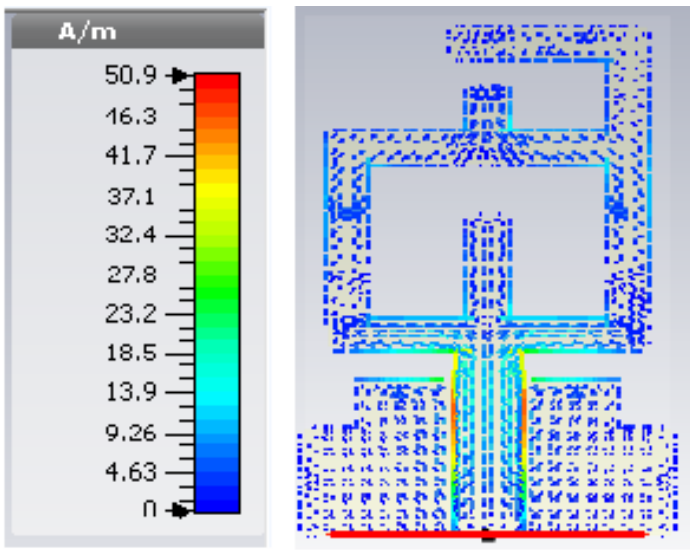

(d)

Fig.5 (a), (b), (c) and (d) are Shows the current distribution

In Fig 5(a), (b), (c) and (d), Furthermore exploration of the triple band operation mechanism, the surface current distribution of proposed antenna at frequency range $2 \mathrm{GHz}$ to $8 \mathrm{GHz}$. In order to better understand the proposed antenna behaviour the current distribution of the proposed antenna at the frequency of $5 \mathrm{GHz}, 2.4 \mathrm{GHz}, 3.5$ $\mathrm{GHz}, 5.8 \mathrm{GHz}$ are simulated.
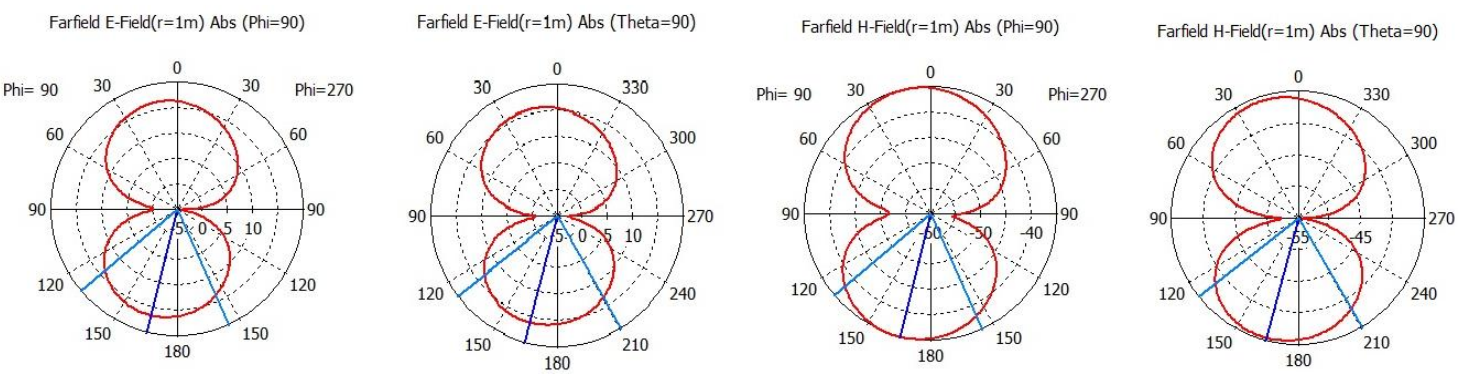

Fig.6 (a), (b), (c) and (d) are Shows the E-field and H-field 
In the above fig 6, E-field and H-field plot at $\left(\mathrm{Phi}=90^{\circ}\right)$ or $\left(\right.$ Theta $\left.=90^{\circ}\right)$ Show that the antenna has a directional radiation pattern By using $\mathrm{E}$ - field or $\mathrm{H}$-field plot we can determine the radiation pattern of the antenna.

\section{Outcomes}

Table 2. Ccomparative results of Antenna1, Antenna2 Antenna3 and the proposed antenna

\begin{tabular}{|c|c|c|c|c|c|c|}
\hline & Frequency Range & $\begin{array}{c}\text { Operating } \\
\text { Frequency }\end{array}$ & $|\mathrm{S} 11|(\mathrm{dB})$ & VSWR & BW (\%) & Gain (dBi) \\
\hline \multirow{3}{*}{ Antenna 1 } & $3.03-3.7$ & 3.5 & -17.74 & 1.2 & 19.91 & 1.58 \\
\cline { 2 - 7 } & $4.9-7.5$ & 5.8 & -23.288 & 1.18 & 41.93 & $2.5(3.27 \mathrm{Max})$ \\
\hline \multirow{2}{*}{ Antenna 2 } & $3.3-4.7$ & 3.5 & -16.37 & 1.35 & 35 & 2.04 \\
\cline { 2 - 7 } & $6.6-7.7$ & 7.28 & -14.63 & 1.41 & 15.38 & 5.4 \\
\hline Antenna 3 & $2.6-3.4$ & 2.95 & -31.381 & 1.05 & 26.67 & 2.10 \\
\cline { 2 - 7 } & $5.6-7.0$ & 6.2 & -17.289 & 1.20 & 22.22 & 3.47 \\
\hline \multirow{3}{*}{$\begin{array}{c}\text { Proposed } \\
\text { Antenna }\end{array}$} & $2.37-2.75$ & 2.5 & -23.719 & 1.0778 & 14.84 & $2.74 \& 3.16(\mathrm{Max})$ \\
\cline { 2 - 7 } & $3.4-3.7$ & 3.5 & -36.1 & 1.027 & 8.45 & $2.58 \& 2.70(\mathrm{Max})$ \\
\cline { 2 - 7 } & $4.6-7.0$ & 5.8 & -36.1 & 1.05 & 41.37 & $3.22 \& 3.74(\mathrm{max})$ \\
\hline
\end{tabular}

\section{Conclusions}

In the previous few decades, the quickly rising requirement of high data rate communication has ready the communication systems the fastest increasing area of communication engineering. Designing, optimization can be done by using CPW-fed for the wireless communication like- Wi-MAX WLAN etc. The concept of CPW-fed has been developing to improve the characteristics of Antenna. A triple band symmetrical CPW-fed antenna is designed to enhance the bandwidth, enhance the gain and return losses etc. This proposed antenna is useful for $2.4 \mathrm{GHz}(2.37-2.75 \mathrm{GHz})$ applications, $3.5 \mathrm{GHz}$ WLAN (3.4-3.7 GHz), 5.15 to $5.35 \mathrm{GHz}$, 5.47 to $5.725 \mathrm{GHz}$, or 5.725 to $5.875 \mathrm{GHz}, 5.9 \mathrm{GHz}(4.6-7.0 \mathrm{GHz})$. In future, the antenna needs to be fabricated, tested and comparison between existing research paper.

\section{References}

[1] A. Balanis, “Antenna theory, analysis and design,” John Wiley \& Sons, New York, 1997.

[2] R. Waterhouse, "Small microstrip patch antenna," Electronics Letters. 31, 604, 1995.

[3] Jean-Sheen Row, "Dual-frequency triangular planar inverted-f antenna," IEEE transactions on antennas and propagation, vol. 53, no. 2, pp. 874-876, February 2005.

[4] Hala A. Eisadek, "CLIP antenna for wireless Bluetooth applications," IEEE Antennas and propagation magazine, vol. 47, no.3, pp. 149-153, June 2005.

[5] B.-K. Ang and B.-K. Chung, "A wideband E-shaped microstrip patch antenna for 5-6 GHz wireless communications," PIER 75, 397-407, 2007.

[6] Sang-Hyuk Wi, Yong-Shik Lee, and Jong-Gwan Yook, "Wideband microstrip patch antenna with Ushaped parasitic elements," IEEE transactions on antennas and propagation, vol. 55, no. 4, pp. 1196-1199, April 2007.

[7] Kim, H., and C.-W. Jung, "Bandwidth enhancement of CPW fed tapered slot antenna with multi transformation characteristics," Electronics Letters, vol. 46, no. 15, 1050-1051, 2010.

[8] Ali A. Dheyab Al-Sajee and Karim A. Hamad, "Improving bandwidth rectangular patch antenna using different thickness of a dielectric substrate," ARPN Journal of Engineering and Applied Sciences, vol. 6, no. 4, April 2011. 
[9] Indrasen Singh, Dr V.S. Tripathi, "Microstrip Patch Antenna and its Applications: a Survey," Int. J. Comp. Tech. Appl., vol 2 (5), pp. 1595-1599, 2011.

[10] Khandelwal, Mukesh Kumar, Kanaujia, Binod Kumar, Dwari, Santanu, Kumar, Sachin Gautam, A. K., "Analysis and design of wideband Microstrip-line-fed antenna with the defected ground structure for Ku band applications," AEU - International Journal of Electronics and Communications, vol. 68, issue 10, pp. 951-957, 2014.

[11] Praveen V. Naidu and Raj Kumar, "A compact dual-band octagonal slotted printed monopole antenna for WLAN/ WiMAX and UWB applications," Journal of Microwaves, Optoelectronics and Electromagnetic Applications, vol. 14, no. 1, June 2015.

[12] Amar Sharma, Puneet Khanna, Kshitij Shinghal, and Arun Kumar, "Design of cpw-fed antenna with a defected substrate for wideband applications," Hindawi Publishing Corporation Journal of Electrical and Computer Engineering volume 2016.

[13] Ahmed Zakaria,Manouare, Saida Ibnyaich, Abdelaziz EL Idrissi, Abdelilah Ghammaz, "A Compact DualBand CPW-Fed Planar Monopole Antenna for 2.62-2.73 GHz Frequency Band, WiMAX and WLAN Applications", Journal of Microwaves, Optoelectronics and Electromagnetic Applications, vol. 16, no. 2, June 2017.

\section{Authors' Profiles}

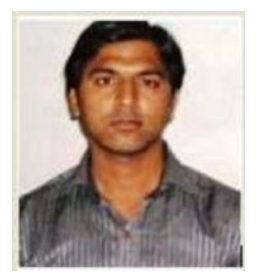

Rahul Tiwari received the M.E. degree in CCN from MITS Gwalior, M.P. India in 2011. Presently, he has been working as an assistant professor at the ECE department of MediCaps University, Indore, India. His research interests include microstrip patch antenna, CPW-Fed patch antenna, and reconfigurable antenna.

Laxman Yogi received the M.E. degree in DC from MU, Indore, His research interest in microwave engineering.

How to cite this paper: Rahul Tiwari, Laxman Yogi, Ashish Bagwari, Vivek Singh Kushwah, "Design and Performance Analysis of a Triple Band Micro-Strip Patch Antenna with CPW-Fed", International Journal of Wireless and Microwave Technologies(IJWMT), Vol.9, No.1, pp. 36-42, 2019.DOI: 10.5815/ijwmt.2019.01.04 